\title{
Penggunaan Resin Hasil Sekresi Kutu Lak pada Pembuatan Biokomposit dari Sabut Kelapa
}

\author{
The Involving Laccifer Lacca Kerr as Resin to Fabricate Coconut Husk Biocomposite
}

\author{
Axel Adam Hermawan, Axl Ariesta, Adi Ilcham* dan Sri Wahyu Murni \\ Jurusan Teknik Kimia UPN “Veteran” Yogyakarta, \\ Jl. Lingkar Utara Condongcatur
}

\author{
Artikel histori : \\ Diterima 02 Maret 2021 \\ Diterima dalam revisi 08 Mei 2021 \\ Diterima 11 Juni 2021 \\ Online 12 Agustus 2021
}

\begin{abstract}
ABSTRAK: Sekresi kutu lak (SKL) merupakan resin yang dihasilkan oleh kutu lak yang hidup di pepohonan. Resin ini dapat dimanfaatkan sebagai bahan perekat pada pembuatan biokomposit bersama sabut kelapa. Penelitian ini bertujuan mempelajari penggunaan SKL pada pembuatan komposit berbahan dasar sabut kelapa dengan mempelajari perbandingan bahan terhadap sifat-sifat fisis biokomposit. Pada penelitian ini mula-mula sabut kelapa yang telah dibersihkan dan dirajang dicampur bersama SKL dan alkohol untuk membuat adonan komposit. Selanjutnya adonan dipres pada $100^{\circ} \mathrm{C}$ dan tekanan tertentu. Setelah komposit dibiarkan mendingin secara alami, biokomposit yang dihasilkan diuji sifat-sifatnya. Untuk mempelajari sifat-sifatnya, biokomposit dibuat dengan berbagai perbandingan baku yaitu antara massa sabut kelapa dan volume SKL yang digunakan. Perbandingan bahan sabut kelapa:sekresi kutu lak yang digunakan adalah berkisar dari $0,6 \mathrm{~g} / \mathrm{mL}$ sampai $1,4 \mathrm{~g} / \mathrm{mL}$. Kemudian sampel ditekan pada suhu $100^{\circ} \mathrm{C}$ dan dipertahankan selama 15 menit sambil dilakukan pengepresan 130 psig. Pengujian kuat tarik produk yang dihasilkan dilakukan berdasar ASTM D-638 dan karakterisasi lainnya berdasar Standar Nasional Indonesia (SNI) 03-2105-2006. Setelah dilakukan karakterisasi terhadap sampel biokomposit yang dibuat diketahui bahwa produk yang dihasilkan memiliki beragam sifat. Oleh karena itu diambil sifat rata-ratanya. Sifat komposit yang dihasilkan adalah: kerapatan sebesar $0,45 \mathrm{~g} / \mathrm{cm}^{3}$, kandungan air $8,8 \%$ (syarat SNI maksimal 14\%), derajat penggembungan $67,6 \%$, kuat tarik $43,4 \mathrm{kgf} / \mathrm{cm}^{2}$ (syarat SNI minimal 3,1 kgf/ $\mathrm{cm}^{2}$ ), modulus Young $1219,2 \mathrm{kgf} / \mathrm{cm}^{2}$, elongasi $67,7 \%$, konduktivitas $1,810^{-8} / \Omega$.m. Sebagian sifat ini sudah memenuhi standar nasional Indonesia (SNI).
\end{abstract}

Kata Kunci: biokomposit, sekreski kutu lak, sabut, kelapa, SNI

\begin{abstract}
:
Nowadays, biocomposite materials are required for particular needs. Coconut husk has a potential to be biocomposite using a resin produced by the laccifer lacca kerr (kerria lacca), an insect. This work was aimed to study the use of the lacca kerr resin to produce a biocomposite of coconut coir based. In the experimental, firstly, the cleaned coconut husks were chopped then mixed with lacca kerr resin and alcohol to make a composite dough. Then the dough were pressed with 130 psig at a $100^{\circ} \mathrm{C}$ within 15 minutes. After that, the biocomposite was allowed to ambient temperature, then it properties were observed. To find the best product properties, the ratio of basic materials were varied. The ratio of coconut husk: lacca kerr resin was used ranged from $0.6 \mathrm{~g} / \mathrm{mL}$ to $1.4 \mathrm{~g} / \mathrm{mL}$. The characterization of product properties were carried out based on ASTM D-638 and under guidance of the Indonesian National Standard (SNI) 03-2105-2006. Based on results, it was found that the best biocomposite observed had properties such as density of $0.45 \mathrm{~g} / \mathrm{cm}^{3}$, water content of $8.8 \%$ (maximum SNI requirement of 14\%), degree of swelling of $67.6 \%$, tensile strength of 43.4 $\mathrm{kgf} / \mathrm{cm}^{2}$ (minimum SNI requirement of $3,1 \mathrm{kgf} / \mathrm{cm}^{2}$ ), Young's modulus of $1219.2 \mathrm{kgf} / \mathrm{cm}^{2}$, elongation of $67.7 \%$, conductivity of $1.810^{-8} / \Omega$.m. Some of these characteristics have met the Indonesian national standard (SNI).
\end{abstract}

Keywords: biocomposite, lacca kerr resin, husk, coconut, SNI 


\section{Pendahuluan}

Penggunaan bahan komposit dalam kehidupan sehari-hari bukanlah hal baru. Sejak ribuan tahun manusia telah memadukan bahan-bahan di sekitar kehidupan untuk memenuhi kebutuhannya seperti dalam pembuatan tempat tinggal. Di sekitar tahun 1940-an bahan-bahan alami berbentuk komposit telah digunakan sebagai pelengkap di mobil-mobil buatan Ford (Błędzki, et al., 2012). Bahan biokomposit telah juga digunakan dalam berbagai keperluan seperti di kendaran dan teranportasi laut (Reddy dkk., 2016).

Penggunaan biokomposit terus dikembangkan disebabkan ramah lingkungan dan tentunya lebih murah. Sebagai contoh pembutan biokomposit dari polimer telah dilaporkan oleh beberapa peneliti (Aminur et al., 2015). Dalam upaya pembuatan biokomposit menggunakan bahan-bahan yang mudah diperoleh, kutu lak dapat menjadi alternatif yang perlu dilakukan. Penggunakan kutu lak sebagai bahan biokomposit pernah dilaporkan oleh peneliti (Roaheti et al., 2015) dengan memadukan serat rami. Secara prinsip penggunaan rami lebih baik akan tetapi mendapatkan serat rami tidaklah mudah. Oleh karena itu dicoba pembuatan biokomposit menggunakan sabut kelapa yang diapadukan dengan kutu lak.

Kutu lak (laccifer lacca kerr) adalah jenis serangga yang termasuk famili Kerridae ordo Hemiptera, hidup secara parasitik pada pepohonan seperti pada pohon kesambi. Kutu lak menghasilkan sejenis resin sebagai alat perlindungan diri dan menempel pada ranting pohon induk (Sujatmoko, 2009). Sekresi kutu lak (SKL) dapat digunakan untuk pembuatan shellac yang memiliki daya rekat yang baik, konduktivitas rendah dan koefisien ekspansi kecil (Singh, 2006). SKL telah digunakan juga sebagai bahan baku untuk industri elektrokimia, percetakan, tekstil, pakaian, kosmetik, isolasi listrik, bahan piringan hitam, bahan tinta cetak, bahan perekat, dan bahan campuran dalam industri semir sepatu (Sharma, et al., 2006). Di Indonesia, tanaman Kesambi merupakan tanaman yang diprioritaskan untuk digunakan sebagai tanaman inang dalam budidaya kutu lak (Taskirawati, dkk, 2007). Bentuk dari sekresi kutu lak dapat dilihat pada Gambar 1.

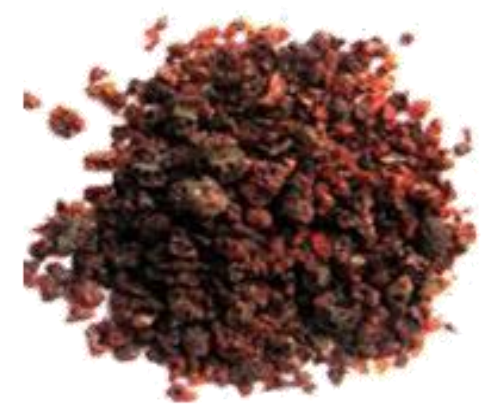

Gambar 1. Bentuk sekresi kutu lak

Struktur kimia kutu lak sangatlah komplek dan utamanya terdiri dari berbagai asam, asam aleuritis dan asam jalaris (Obradovic et al., 2017) sebagai mana ditunjukkan di Gambar 2. Menurut Reshma et al., (2018) kutu lak terdiri dari resin berjumlah 68 sampai 90\%, dye berjumlah 2 sampai $10 \%$, malam berjumlah 5 sampai $6 \%$, bahan-bahan mineral berjumlah 3 sampai $7 \%$ bahan albuminous berjumlah 5 sampai 10\%, dan air berjumlah 2 sampai $3 \%$.<smiles>O=C(O)CCCCCCC[C@@H](O)[C@H](O)CCCCCCO</smiles>

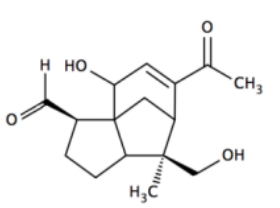

Jalaric acid

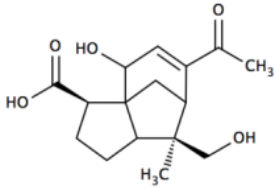

Shellolic acid
Gambar 2. Struktur penyusun resin kutu lak

Mengingat sifatnya yang khas, SKL dapat digunakan untuk pembuatan biokomposit bersama sabut kelapa. Dengan adanya gugus fungsional pada SKL sebagaimana di Gambar 2 menurut (Rohaeti dkk., 2015) gugus (-COOH) dan $\mathrm{OH}$ memungkinkan SKL dapat larut dalam alkohol. Dengan membentuk larutan bersama alkohol, SKL dapat difungsikan sebagai perekat pada pembentukan komposit bersama sabut kelapa.

Pemanfaatan sabut kelapa dalam kehidupan seharisehari secara tradisional telah lazim dilakukan seperti dijadikan bantal, karpet, tikar. Dalam sabut kelapa, terdapat $26 \%$ air, $14,25 \%$ pektin, $8,5 \%$ hemiselulosa, $29,23 \%$ lignin, dan selulosa $21,07 \%$. Serat sabut kelapa memiliki sifatsifat antara lain tegangan tarik yang tinggi, tidak larut dalam air, dan pelarut organik.

Sebagai serat, sabut kelapa terdiri dari selulosa berbentuk polimer dengan sifat mekanis antara lain kerapatan sebesar $1.2 \mathrm{~g} / \mathrm{cm}^{3}$, elongation $30 \%$, tensile strength $175 \mathrm{MPa}$, modulus Young 4-6 Gpa, water absorption (\%)130-180 (Lumintang dkk, 2011). Bila dibandingkan sabut kelapa memiliki kekuatan tarik lebih tinggai dari beberapa bahan lain (Satyanarayana et al., 1982). Ketika digunakan sebagai Sebagai Perbandingan kekuatan perekat berkisar antara 528 sampai $918 \mathrm{~kg}$ massa (Nur, 2017).

Komposit merupakan material yang dihasilkan dari penggabungan dua bahan yang fasanya berbeda. Bahan pertama disebut fasa primer atau matrik sedangkan fasa kedua disebut fasa sekunder atau disebut penguat (Groover, 2010). Kadang-kadang komposit yang terbentuk dari bahan-bahan alami atau disebut biokomposit dibutuhkan karena memiliki sifat mekanik yang baik, tidak mudah korosif, bahan baku yang mudah diperoleh dengan harga yang murah, dan memiliki massa jenis yang lebih rendah (Herwandi dkk, 2014).

Agar sebuah bahan komposit dapat digunakan harus memiliki beberapa kriteria seperti konduktivitas, kerapatan, 
derajat penggembungan, kadar air, sifat mekanik. Konduktivitas merupakan ukuran kemampuan bahan menyampaikan daya hantar listrik. Sifat konduktivitas pada suatu material dapat diubah-ubah dengan menambahkan material lain yang biasa disebut dengan doping yang dapat meningkatkan pembawa mayoritas elektron atau lubang (hole) pada suatu material (Elly, 2009). Kerapatan merupakan faktor penting dalam produk komposit, dimana sifat ini sangat berpengaruh terhadap sifat fisis dan mekanis biokomposit yang dihasilkan (Jatmiko, 2006). Derajat penggembungan dapat menunjukkan ada atau tidaknya ikatan silang (chemical crosslink) pada biokomposit. Semakin banyak ikatan silang maka biokomposit sulit menyerap air. Polimer-polimer yang tidak memiliki ikatan silang (linier atau bercabang) biasanya mudah larut dalam beberapa pelarut, mudah melebur, dan mengalir (Stevens, 2001). Kadar air pada biokomposit berpengaruh pada karakter biokomposit. Pada komposit partikel kayu, kandungan air akan semakin rendah dengan meningkatnya kadar perekat yang digunakan disebabkan kontak partikel dengan perekat menahan masuknya air di sela-sela partikel kayu (Jatmiko, 2006). Sifat Mekanik sebuah bahan merupakan sifat yang sangat penting. Di antara sifat-sifat mekanis bahan yang perlu diketahui adalah modulus young, kuat putus, regangan (Shah, 2007).

Tujuan penelitian ini adalah mempelajari pembuatan biokomposit yang terbuat dari sabut kelapa dan sekresi kutu lak. Dalam hal ini sekresi kutu lak bertindak sebagai filler sekaligus sebagai perekat. Variabel yang dipelajari adalah perbandingan bahan pembentuknya dengan sifat-sifat produk berupa kerapatan, derajat penggabungan, kadar air, dan sifat mekanik serta konduktivitas.

\section{Metode Penelitian}

Bahan-bahan utama dalam penelitian pembuatan biokomposit ini adalah sabut kelapa dan sekresi kutu lak. Sabut kelapa yang digunakan merupakan varietas cocos nucifera $L$ yang diperoleh di daerah Wates, Kulon Progo, Daerah Istimewa Yogyakarta. Sekresi kutu lak diperoleh dari PT. Banyukerto, Probolinggo, Jawa Timur. Alkohol yang digunakan adalah etanol teknis diperoleh dari toko bahan kimia lokal.

Pertama-tama sabut kelapa dibersihkan dan dijemur di bawah sinar matahari supaya kandungan air dalam sabut kelapa kurang dari 14\% sesuai persyaratan yang ditentukan oleh Standar Nasional Indonesia (SNI) 03-2105-2006. Setelah penjemuran, sabut kelapa dipotong kecil-kecil dengan panjang $1 \mathrm{~cm}$. Sabut kelapa kemudian diletakkan dalam cetakan aluminium yang berukuran $180 \mathrm{~mm}$ x 180 $\mathrm{mm} \times 8 \mathrm{~mm}$ sesuai SNI 03-2105-2006 dalam posisi berjajar. Berikutnya larutan yang terdiri dari etanol dan sekresi kutu lak dengan perbandingan volume 1:2 dituangkan ke cetakan aluminium yang berisi sabut kelapa. Cetakan kemudian dimasukkan ke dalam mesin hot press yang diatur suhunya $100^{\circ} \mathrm{C}$ dan dipertahankan selama 15 menit sambil dilakukan pengepresan 130 psig. Pengepresan bertujuan memberi tekanan dan memaksa matriks menjadi lapisan yang lebih kompak dengan permukaan serat yang direkat.

Setelah pengepresan, hasilnya didinginkan pada suhu kamar. Produk biokomposit yang dihasilkan siap untuk dikarakterisasi dengan uji konduktivitas, kerapatan, derajat penggembungan (swelling), daya serap kadar air, dan sifat mekanik. Untuk uji kuat tarik dilakukan berdasarkan metoda ASTM D-638.

Uji derajat penggembungan dilakukan dengan memasukan air ke dalam biokomposit yang telah dibuat. Cara ini dilakukan dengan merendam biokomposit dalam air selama 24 jam kemudian ditimbang. Derajat penggembungan dihitung dengan persamaan berikut: berat air dalam komposit dibagi berat komposit kering (Rohaeti dkk, 2015).

\section{Hasil dan Pembahasan}

Hasil pengukuran sifat-sifat biokomposit yang terbuat dari sabut kelapa dan matriks SKL dengan variasi perbandingan bahan ditunjukkan oleh Gambar 3 s.d 8. Pada pengujian sifat komposit yang dibuat, tidak semua pengujian berhasil dilakukan baik. Ada sebagian pengujian yang menghasilkan data yang tidak konsisten sehingga data ini dianggap tidak valid.

\subsection{Kerapatan}

Pada pengukuran kerapatan komposit dilakukan dengan menimbang massa bahan dibagi volumenya. Secara prinsip uji ini mengikuti prosedur yang dikeluarkan oleh SNI 03-2105-2006. Ditinjau dari kerapatannya, perbandingan bahan pembentuk awal berpengaruh pada kerapatan biokomposit yang dihasilkan. Sebagaimana ditunjukkan oleh Gambar 3 terjadi kecenderungan penurunan kerapatan bila jumlah kutu lak dalam campuran bahan baku makin sedikit. Kutu lak dalam hal ini telah menjadi pembuka rongga antara sabut kelapa sekaligus faktor yang menentukan kerapatan. Sehingga semakin sedikit kandungan kutu lak dalam campuran menyebabkan kerapatan produk makin rendah.

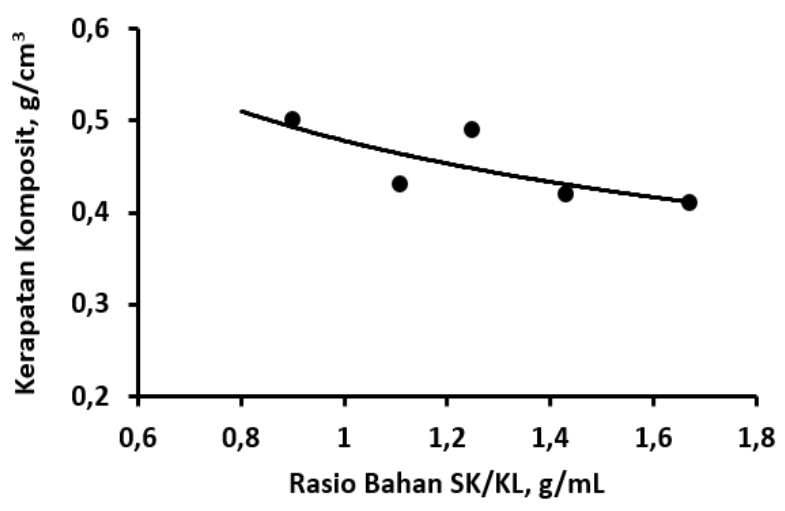

Gambar 3. Kerapatan komposit pada berbagai rasio bahan 
Selama bahan dipanaskan, molekul-molekul yang ada dalam bahan memiliki energi untuk saling menjauh dan bergerak ke segala arah. Akibatnya volume bahan semakin besar tapi tidak terjadi penambahan massa. Dapat dilihat dari Gambar 3 besarnya kerapatan biokomposit tidak terlalu banyak berubah yaitu berkisar antara $0,3 \mathrm{gram} / \mathrm{cm}^{3}$ $0,5 \mathrm{gram} / \mathrm{cm}^{3}$. Dengan demikian produk biokomposit yang dihasilkan memenuhi SNI 03-2105-2006 yang mengharuskan produk komposit harus memiliki kerapatan berkisar antara 0,4 gram $/ \mathrm{cm}^{3}-0,9 \mathrm{gram} / \mathrm{cm}^{3}$ sebagaimana komposit pada papan partikel.

\subsection{Derajat Penggembungan}

Derajat pengembungan merupakan salah satu parameter yang harus diketahui pada komposit yang dihasilkan. Pada karakterisasi ini biokomposit diuji daya serap terhadap air dengan cara direndam dalam air dan ditimbang. Derajat penggembungan dihitung sebagai berikut.

$$
\text { derajat penggembungan }(\%)=\frac{m w-m d}{m d} \times 100 \%
$$

Dengan $m w$ adalah biokomposit setelah direndam dalam air, dan $m d$ adalah biokomposit mula-mula. Hasil penimbangan keseluruhan disajikan pada Gambar 4.

Berdasarkan Gambar 4, derajat penggembungan sedikit dipengaruhi oleh jumlah kutu lak. Semakin sedikit kutu lak derajat penggembungan semakin rendah. Ini artinya SKL merupakan bahan yang mudah berinteraksi dengan air. Tentunya penggunaan SKL yang sedikit akan lebih baik bagi produk komposit yang dihasilkan.

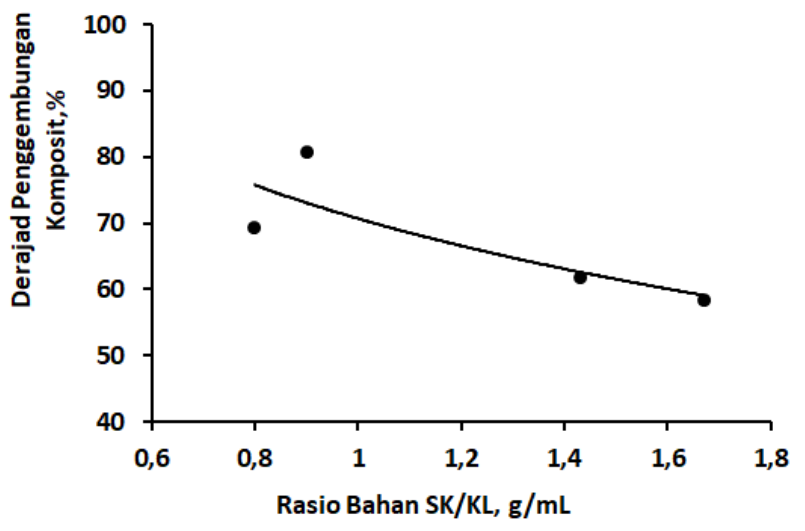

Gambar 4. Derajat penggembungan komposit pada berbagai rasio bahan

\subsection{Kuat Tarik}

Pada Gambar 5 terlihat bahwa kuat tarik biokomposit meningkat seiring menurunnya perbandingan bahan baku antara sabut kelapa dan kutu lak. Hal ini menjelaskan bahwa keberadaan sabut kelapa sangat berperan pada sifat kuat tarik. Jumlah sabut kelapa yang lebih banyak menyebabkan terbentuknya ikatan silang yang lebih banyak (Jatmiko, 2006, Das dan Biswas, 2016). Material dengan jumlah ikatan silang yang banyak berarti diantara rantai molekul saling berikatan sangat kuat, sehingga ketika diberi gaya material tersebut dapat menahan beban lebih besar.

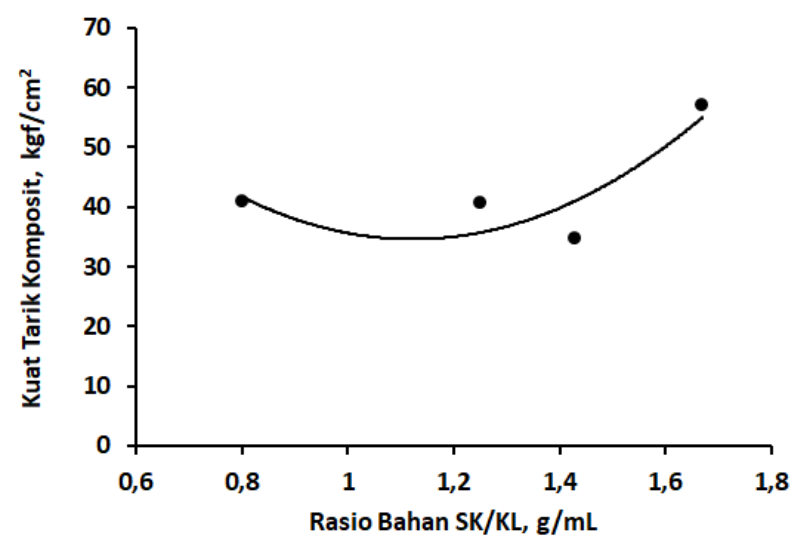

Gambar 5. Kuat tarik komposit pada berbagai rasio bahan

\subsection{Modulus Young}

Pada Gambar 6 terlihat bahwa modulus Young meningkat dengan bertambahnya jumlah sabut kelapa. Hal ini disebabkan bertambahnya sifat mekanis sabut kelapa yang memiliki tensile strength tinggi (Lumintang dkk., 2011).

Modulus Young dipengaruhi oleh kristanilitas, ikatan silang, massa molekul, panjang rantai, dan percabangan rantai. Biokomposit yang terbuat dari sabut kelapa dan sekresi kutu lak dengan kandungan rasio bahan 1,6 menghasilkan komposit yang memiliki modulus Young tertinggi. Akan tetapi derajat penggembungan kompositnya lebih rendah. Ini menunjukan ikatan silang pada komposit sangat banyak dan memberi kontribusi pada tingginya modulus Young pada biokomposit.

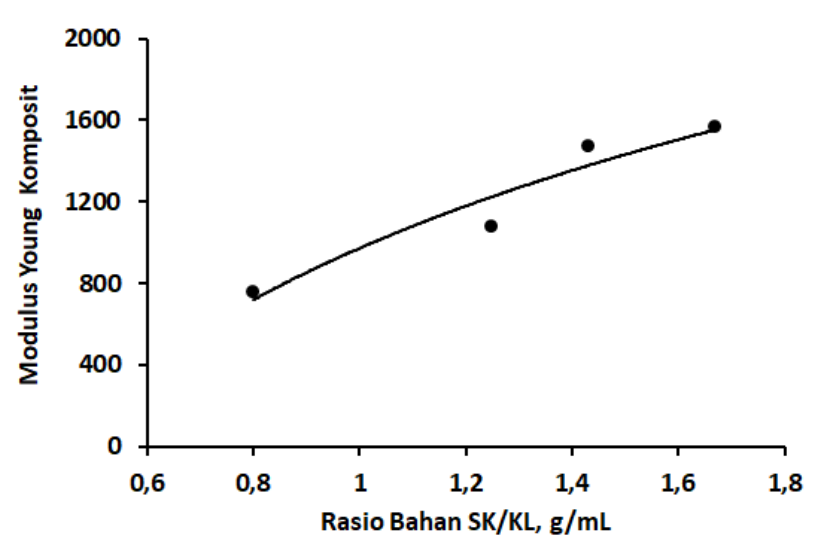

Gambar 6 Modulus Young komposit pada berbagai rasio bahan

\subsection{Elongasi}

Hasil pengukuran elongsi biokomposit ditunjukan oleh Gambar 7. Dengan meningkatnya perbandingan jumlah 
bahan baku sabut kelapa terhadap SKL elongasi cenderung mengalami penurunan. Hal ini menjelaskan bahwa penambahan jumlah sabut kelapa akan menurunkan kelenturan biokomposit. Sebaliknya jumlah SKL yang semakin banyak akan meningkatkan elongasi komposit. Pada masalah-masalah tertentu, dibutuhkan bahan dengan daya lentur yang tinggi. Untuk itu penggunaan SKL yang lebih banyak lebih menguntungkan.

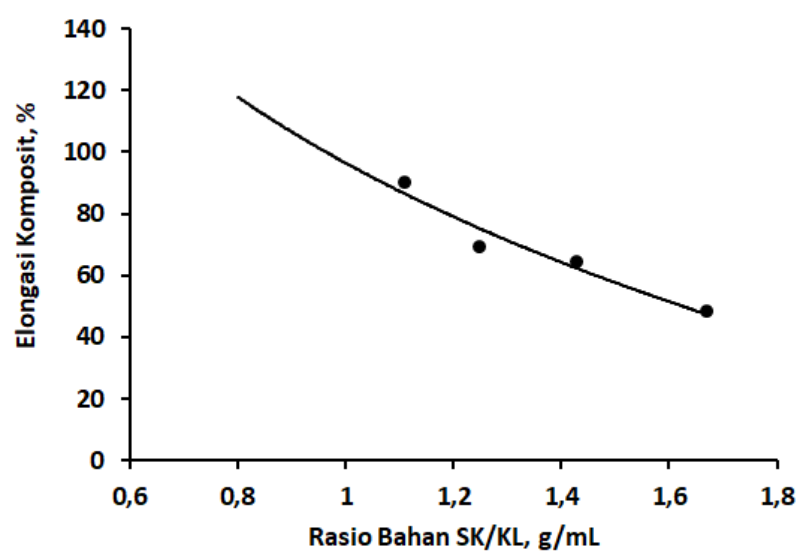

Gambar 7. Elongasi komposit pada berbagai rasio bahan

\subsection{Konduktivitas}

Hasil pengukuran konduktivitas biokomposit yang terbuat dari sabut kelapa dan SKL pada berbagai komposisi dengan alat El-kahfi 100 ditunjukkan pada Gambar 8. Komposit tersusun dari bahan-bahan yang sulit menghantarkan listrik. Sabut kelapa bukanlah bahan yang bagus untuk menghantarkan listik.

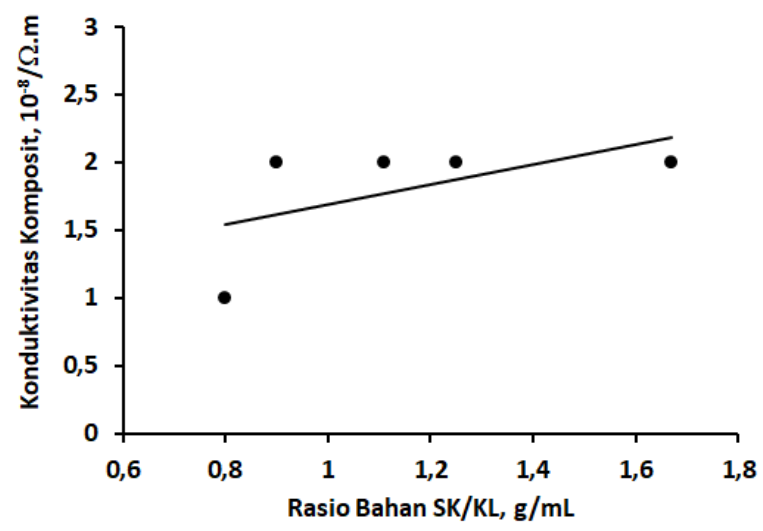

Gambar 8. Konduktivitas komposit pada berbagai rasio bahan

Demikian juga dengan SKL. Kemungkinan daya hantar listrik yang kecil disebabkan oleh adanya gugus $\mathrm{OH}$ pada alkohol atau sedikit air yang terkandung pada sabut kelapa. Oleh karena itu konduktivitas biokomposit tidak banyak terpengaruh meskipun perbandingan bahan baku diubah- ubah. Dengan demikian produk biokomposit yang dihasilkan berpotensi digunakan sebagai bahan insulasi.

\section{Kesimpulan}

Dari pembahasan sebelumnya diketahui penggunaan SKL dapat mempengaruhi sifat-sifat produk biokomposit yang dihasilkan. Penggunaan SKL yang lebih sedikit akan lebih menguntungkan karena daya serap terhadap air lebih kecil tapi kuat tarik dan modulus young lebih besar. Elongasi yang rendah merupakan kekurangan dari produk tapi lebih menguntungkan bila akan digunakan sebagai bahan isolator.

Berdasarkan pembahasan dapat pula ditarik kesimpulan bahwa sifat rata-rata komposit yang dihasilkan adalah: kerapatan sebesar $0,45 \mathrm{~g} / \mathrm{cm}^{3}$, derajat penggembungan $67,6 \%$, kuat tarik $43,4 \mathrm{kgf} / \mathrm{cm}^{2}$, modulus Young 1219,2 kgf/cm², elongasi $67,7 \%$, konduktivitas 1,8 $10^{-8} / \Omega$.m. Sebagian sifat ini sudah memenuhi standar nasional Indonesia (SNI).

\section{Daftar Pustaka}

Sujatmoko, S., 2009, Parasites and Predators of Laccifer lacca Kerr on Lac Culture in East Sumba, East Nusa Tenggara, Journal of Forestry Research Vol.6 No.2 2009: 112-125.

Rohaeti, E., Mujiyono, Rochmadi (2015). Biokomposit dari serat rami dan sekresi kutu lak termodifikasi dengan lateks terhidrasi dan tidak terhidrasi. Majalah kulit, karet, dan plastik vol.31 No.1, 23-35.

Herwandi, Sugianto, Somawardi, M. Subhan, 2014. Pengaruh volume serat rekel terhadap kekuatan tarik dan impact komposit sebagai bahan pembuatan dashboard mobil. Prosiding Seminar Nasional Sains dan Teknologi, 1-6.

Taskirawati, I., Suratmo, F. G., D. Darusman, Haneda, N.F, 2007, Peluang Investasi Usaha Budidaya Kutu Lak (Laccifer lacca Kerr) : Studi Kasus di KPH Probolinggo Perum Perhutani Unit II. Jurnal Perennial. 4(1), 23-27.

Jatmiko, A., 2006. Kualitas Papan Partikel Pada Berbagai Kadar Perekat Likuida Tandan Kosong Kelapa Sawit. Skripsi. Sumatera Selatan: Teknik Kimia Politeknik Negeri Sriwijaya.

Satyanarayana, K. G., Pillai, C. K. S., Sukumaran, K., S. G. Pillai, K., Rohatgi, P. K., Vijayan, K. 1982, Structure property studies of fibres from various parts of the coconut tree. Journal of materials science 17, 24532462.

Groover, M.P., 2010, Fundamentals of Modern Manufacturing Material, Processes, and System 4th edition. John Willey \& Sons, Inc.

Elly, N., 2009, Analisis sifat konduktivitas listrik selulosa microbial dari Limbah tahu (Whey) dengan Doping Kalium (K). Skripsi. Jakarta: FMIPA Universitas Indonesia. 
Lumintang, R.C.A., Soenoko, R., Wahyudi, S., 2011, Komposit hibrid polyester berpenguat serbuk batang dan serat sabut kelapa. Jurnal rekayasa mesin, 145153.

Sharma, K.K., Jaiswal, A.K., and Kumar, K.K., 2006, Role of lac culture in biodiversity conservation: issues at stake and conservation strategy. Current Science. 91 (7) : 894-898.

Singh, R., 2006, Applied Zoology Lac Culture. National Science Digital Library at Niscair, India.

Stevens, M.P., 2001. Kimia Polimer. Penerjemah: Lis Sopyan. Jakarta: Pradnya Paramita.

Shah, V.. 2007. Handbook Of Plastics Testing And Failure Analysis 3rd edition. John Willey \& Sons, Inc.

Das, G., Biswas, S., 2016, Physical, Mechanical and Water Absorption Behaviour of Coir Fiber Reinforced Epoxy Composites Filled With $\mathrm{Al}_{2} \mathrm{O}_{3}$ Particulates, 5th National Conference on Processing and Characterization of Materials IOP Publishing, IOP Conf. Series: Materials Science and Engineering 115 (2016) 012012.

Reddy, T.R.K., Kim, H.J. Park, J.W., 2016, Renewable Biocomposite Properties and their Applications, Book Chapter. Composites from Renewable and Sustainable Materials. Intechopen. DOI: 10.5772/62936
Obradovic, J., Petibon, F., Fardim, P., 2017, Preparation and Characterisation of Cellulose-Shellac Biocomposites, BioResources 12(1), 1943-1959, 2017.

Reshma, B. V., Manohar, R.N., Anaha, V.I., 2018, A review on laccifer lacca, World Journal of Pharmaceutical Research SJIF, Volume 7, Issue 10, 206-218.

Aminur, Hasbi, M., Gunawan, Y., 2015, Proses pembuatan biokomposit polimer serat untuk aplikasi kampas rem, Seminar Nasional Sains dan Teknologi 2015 Fakultas Teknik Universitas Muhammadiyah Jakarta, 17 November 2015.

Błędzki, A.K., Jaszkiewicz, A., Urbaniak, M., Walczak, D.S., 2012. Biocomposites in the Past and in the Future A, FIBRES \& TEXTILES in Eastern Europe, 20, 6B (96): 15-22.

Nur, P., 2017, Mana Jenis Lem untuk Kayu yang Lebih Kuat: PVAc vs Lem lain, 2 May 2017, https://www.lemkayu.net/mana-jenis-lem-untuk-kayuyang-lebih-kuat-pvac-vs-lem-lain-2382.html 